\title{
Exploring the Heterogeneity of Factors that may Influence Implementation of PrEP in Family Planning Clinics: A Latent Profile Analysis
}

Kaitlin N Piper ( $\sim$ kaitlin.piper@emory.edu )

Emory University https://orcid.org/0000-0001-9422-1565

Regine Haardörfer

Emory University

Cam Escoffery

Emory University

Anandi N Sheth

Emory University

Jessica Sales

Emory University

\section{Research}

Keywords: implementation science, PrEP, HIV/AIDS, Family Planning, Consolidated Framework for Implementation Research, latent profile analysis

Posted Date: August 27th, 2020

DOI: https://doi.org/10.21203/rs.3.rs-63449/v1

License: (c) (i) This work is licensed under a Creative Commons Attribution 4.0 International License. Read Full License

Version of Record: A version of this preprint was published at Implementation Science Communications on May 4th, 2021. See the published version at https://doi.org/10.1186/s43058-021-00148-3. 


\section{Abstract}

Background: Title X-funded family planning clinics have been identified as optimal sites for delivery of pre-exposure prophylaxis (PrEP) for HIV prevention. However, PrEP has not been widely integrated into family planning services, especially in the Southern U.S., and data suggest there may be significant implementation challenges in this setting. Because Title $X$ clinics vary greatly in provider-, organizational-, and systems-level characteristics, there is likely variation in capacity to implement PrEP across clinics.

Methods: We conducted a survey from February-June 2018 among providers and administrators of non-PrEP providing Title Xfunded clinics across 18 southern states. Survey items were designed using the Consolidated Framework for Implementation Research (CFIR) to assess constructs relevant to PrEP implementation. To explore the heterogeneity of CFIR-related determinants and identify distinct sub-groups of Title $X$ clinics, a latent profile analysis was conducted using nine CFIR constructs: complexity, relative advantage, cost, attitudes, implementation climate, compatibility, leadership engagement, available resources, and cosmopolitanism. We then conducted a multi-level analysis (accounting for nesting of participants within clinics) to test whether group membership was associated with readiness for implementation of PrEP, controlling for key sociodemographic characteristics.

Results: 414 healthcare providers/administrators from 227 non-PrEP providing Title X clinics participated in the study. We identified six sub-groups of clinics that each had distinct patterns of perceptions across the CFIR-related determinants. Clinic sub-groups included: "High Capacity", "Optimistic”, "Advantageous”, "Moderate”, "Incompatible”, and "Resource Constrained". Group membership was related to numerous provider-level (i.e., ability to prescribe medication), clinic-level (i.e., provision of primary care), and community-level characteristics (i.e., county-level HIV prevalence). In comparison to the "Moderate" group (which held neutral perceptions across the CFIR constructs), the "High Capacity" and "Optimistic" groups had significantly higher levels of implementation readiness; and the "Resource Constrained group had a significantly lower level of implementation readiness.

Conclusions: Latent profile analyses can help researchers understand how context-specific implementation determinants vary across individuals and settings (such as clinics), allowing implementation planning to be tailored to the specific needs of each segment of the population.

\section{Contributions To The Literature}

- Healthcare settings can exhibit significant heterogeneity in organizational context and barriers to implementation. Therefore, to promote intervention adoption, implementation plans and strategies may need to be tailored to each organization's unique needs.

- Latent profile analyses can capture heterogeneity in organizational context across settings and promote the identification of unique subgroups within the population.

- This study presents an example of how latent profile analysis can be used to identify subgroups of clinics, allowing implementation planning to be tailored to the specific needs of unique segments of a diverse network of clinical sites.

\section{Background}

Women account for approximately $20 \%$ of all new HIV infections in the United States, with a disproportionate number of new diagnoses occurring in the South $(1,2)$. Effective HIV prevention efforts for women in the South are needed, not only to curb the epidemic among this population, but also to protect their sexual partners and prevent perinatal infection $(1,2)$. HIV Pre-exposure Prophylaxis (PrEP) is a safe and effective intervention to prevent HIV infection, $(3,4)$ but PrEP utilization, access, and awareness remains low among women of all ages in the US (5-9).

In 2017, only 6\% of PrEP users were women, and among the 176,670 heterosexual women for which PrEP was indicated, only $2 \%$ received a prescription (10-13). Particularly, for women in the South, low access to PrEP providing clinics is a major barrier to PrEP utilization $(14,15)$. PrEP is not widely offered in settings that women regularly receive sexual health and preventative 
services, such as women's healthcare and family planning clinics $(6,14-16)$. However, Title X-funded family planning clinics in high HIV incidence settings (such as much of the Southern U.S.) are potentially ideal for expanding PrEP care for women, since they are an important safety net source of care and are already widely utilized by women for sexual health services, including HIV testing $(17,18)$.

A key initiative of the U.S. Department of Health and Human Services' (USDHHS) plan for ending the HIV epidemic is dissemination and implementation ("scale-up") of PrEP (19). However, integration of PrEP into new settings (such as family planning clinics) requires understanding of organizational context and potential obstacles to implementation (20). To identify contextual factors related to implementation, pre-implementation needs assessments, which employ surveys and interviews with clinical stakeholders, can provide critical insight into organizational context and capacity to implement evidence-based interventions (EBIs). To guide needs assessments, implementation science theoretical frameworks, such as the Consolidated Framework for Implementation Research (CFIR), can promote a structured and systematic assessment of constructs that are known to be related to successful adoption of EBIs (21). In prior work, we have found that key CFIR-related correlates of PrEP implementation capacity in family planning clinics include available resources (i.e., time, funding, and staffing), leadership engagement, implementation climate, and provider attitudes about PrEP (22). Identifying barriers prior to adoption is critical, so that implementation plans, or "blueprints" for adoption of EBIs, can delineate strategies for overcoming known obstacles to implementation (23).

To support effective scale-up of EBIs, implementation planning should also account for contextual variation (24-26). Because healthcare settings (such as Title X clinics) can exhibit significant heterogeneity in organizational context and barriers to EBI implementation, "blueprints" may need to be tailored to each organization's unique needs. For instance, clinical settings have shown wide variation in provider-level attitudes towards EBIs (27), organizational-level implementation climate (28), and systems-level policies and funding structures $(29,30)$. Because of this variation, a "one-size-fits-all" approach to implementation planning may not support successful implementation of EBls, such as PrEP.

In this study, we present a method for systematically capturing the contextual variation or heterogeneity in implementation determinants across organizations. Through the use of latent profile analysis (LPA) (31, 32), we identified sub-groups of Title X family planning clinics in the South, that each have unique profiles of CFIR-related barriers and facilitators to implementation. The research question are: (1) what sub-groups represent the heterogeneity of CFIR-related factors among Title X-funded family planning clinics in the South, and (2) how is group membership related to readiness for implementation of PrEP?

\section{Methods}

\section{Study Design}

We invited healthcare providers and clinic administrators from Title X-funded family planning clinics in Department of Health and Human Services (DHHS) Regions III, IV, and VI to participate in an online survey from February through June 2018. These regions include states that comprise the Southern US including Alabama, Arkansas, Delaware, District of Columbia, Florida, Georgia, Kentucky, Louisiana, Maryland, Mississippi, New Mexico, North Carolina, Oklahoma, Pennsylvania, South Carolina, Tennessee, Texas, Virginia, and West Virginia. Quantitative surveys took place online with the assistance of the National Clinical Training Center for Family Planning (NCTCFP). The survey was emailed to the Title X clinic listserv for DHHS Regions III, IV, and $\mathrm{VI}$, and listserv members received one to two email reminders per month. An advertisement for the survey was also posted on the NCTCFP website, and the survey was promoted though engagement with State Title X Grant holders and through in-person recruitment at the biannual NCTCFP national meetings for Title X providers. The survey was guided by CFIR constructs relevant to PrEP implementation. It also collected information on readiness to implement PrEP as well as individual and clinic characteristics. The survey took approximately $15-25$ minutes to complete, and participants received a $\$ 30$ incentive. All procedures and recruitment methods have been described previously (33). Institutional Review Boards from Emory University and University of North Carolina approved the study protocol prior to data collection (See Additional File 1 for STROBE checklist).

\section{Participants}


Providers were defined as individuals who have the potential ability to prescribe, counsel, or screen for PrEP. Clinic administrators were individuals who served in an administrative oversight capacity over the Title X activities in their clinic. Clinic addresses were geocoded to identify participants residing in the same clinic, and each participant and clinic were given a unique identification number. Procedures for geocoding clinics have been described elsewhere (22).

There were 742 individuals who agreed to complete the survey. Of those, 519 (69.9\%) respondents sufficiently completed the survey to warrant inclusion in our analyses. Our analyses used data from all surveys that met a minimal criteria for completeness. In particular, we required the respondent to provide at least one response to questions related to PrEP use in their clinic. For the purposes of this pre-implementation analysis, the sample was restricted to clinics where PrEP was not currently being prescribed. Therefore, our sample included 414 participants from 227 non-PrEP prescribing Title X clinics. On average, there were 1.8 (range: 1-12) participants per clinic.

The mean age of participants was $45.92(S D=11.22)$ years. Participants were predominately White $(n=311,75.12 \%)$ and most were clinic providers $(n=351,84.78 \%)$. The mean number of years serving in their current role was $8.58(S D=7.89)$. Many clinics were located in metropolitan areas $(n=293,70.77 \%)$ with high prevalence of HIV (mean $=459.78$ cases $/ 100,000, S D=512.89$ cases/100,000). See Table 1 for characteristics of the sample. 
Descriptive statistics, by group

\begin{tabular}{|c|c|c|c|c|c|c|c|c|}
\hline & \multicolumn{7}{|c|}{ Mean (SD) or counts (\%) by group } & \multirow{2}{*}{$\begin{array}{l}\text { Full } \\
\text { Sample } \\
\text { M (SD)/ } \\
n(\%) \\
(n= \\
414)\end{array}$} \\
\hline & $\begin{array}{l}\text { High } \\
\text { Capacity } \\
(n=17)\end{array}$ & $\begin{array}{l}\text { Optimistic } \\
(n=105)\end{array}$ & $\begin{array}{l}\text { Advantageous } \\
(n=53)\end{array}$ & $\begin{array}{l}\text { Moderate } \\
(n=201)\end{array}$ & $\begin{array}{l}\text { Incompatible } \\
(\mathrm{n}=26)\end{array}$ & $\begin{array}{l}\text { Resource } \\
\text { Constrained } \\
(n=12)\end{array}$ & $\begin{array}{l}\mathrm{p}- \\
\text { value }\end{array}$ & \\
\hline \multicolumn{9}{|l|}{$\begin{array}{l}\text { CFIR } \\
\text { Constructs }\end{array}$} \\
\hline Complexity & $\begin{array}{l}1.71 \\
(0.69)\end{array}$ & $\begin{array}{l}2.67 \\
(0.91)\end{array}$ & $3.83(0.72)$ & $\begin{array}{l}3.18 \\
(0.69)\end{array}$ & $4.27(0.60)$ & $4.08(0.99)$ & $<001$ & $\begin{array}{l}3.17 \\
(0.94)\end{array}$ \\
\hline Advantage & $\begin{array}{l}3.06 \\
(1.20)\end{array}$ & $\begin{array}{l}3.75 \\
(0.79)\end{array}$ & $3.85(0.74)$ & $\begin{array}{l}2.89 \\
(0.76)\end{array}$ & $2.23(0.76)$ & $3.50(1.24)$ & $\begin{array}{l}< \\
0.001\end{array}$ & $\begin{array}{l}3.21 \\
(0.94)\end{array}$ \\
\hline Cost & $\begin{array}{l}2.97 \\
(0.58)\end{array}$ & $\begin{array}{l}2.87 \\
(0.44)\end{array}$ & $3.89(0.43)$ & $\begin{array}{l}3.28 \\
(0.38)\end{array}$ & $3.85(0.56)$ & $3.71(0.57)$ & $<.001$ & $\begin{array}{l}3.29 \\
(0.55)\end{array}$ \\
\hline $\begin{array}{l}\text { Concerned } \\
\text { Attitudes }\end{array}$ & $\begin{array}{l}2.58 \\
(0.71)\end{array}$ & $\begin{array}{l}2.09 \\
(0.45)\end{array}$ & $2.44(0.51)$ & $\begin{array}{l}2.90 \\
(0.44)\end{array}$ & $3.04(0.42)$ & $1.85(0.47)$ & $<0.001$ & $\begin{array}{l}2.60 \\
(0.60)\end{array}$ \\
\hline Climate & $\begin{array}{l}4.04 \\
(0.56)\end{array}$ & $\begin{array}{l}3.74 \\
(0.56)\end{array}$ & $3.58(0.60)$ & $\begin{array}{l}3.18 \\
(0.40)\end{array}$ & $2.62(0.65)$ & $2.30(0.70)$ & $<.001$ & $\begin{array}{l}3.35 \\
(0.63)\end{array}$ \\
\hline Compatibility & $\begin{array}{l}4.59 \\
(0.52)\end{array}$ & $\begin{array}{l}4.20 \\
(0.43)\end{array}$ & $3.97(0.45)$ & $\begin{array}{l}3.12 \\
(0.46)\end{array}$ & $2.58(0.63)$ & $4.11(0.73)$ & $<.001$ & $\begin{array}{l}3.56 \\
(0.74)\end{array}$ \\
\hline Leadership & $\begin{array}{l}4.59 \\
(0.48)\end{array}$ & $\begin{array}{l}3.43 \\
(0.77)\end{array}$ & $3.56(0.82)$ & $\begin{array}{l}3.61 \\
(0.70)\end{array}$ & $3.15(0.88)$ & $1.42(0.59)$ & $<0.001$ & $\begin{array}{l}3.51 \\
(0.85)\end{array}$ \\
\hline Resources & $\begin{array}{l}4.32 \\
(0.64)\end{array}$ & $\begin{array}{l}3.04 \\
(0.65)\end{array}$ & $2.42(0.67)$ & $\begin{array}{l}2.99 \\
(0.69)\end{array}$ & $2.11(0.85)$ & $1.58(0.73)$ & $<001$ & $\begin{array}{l}2.89 \\
(0.82)\end{array}$ \\
\hline Cosmopolitan & $\begin{array}{l}4.65 \\
(0.49)\end{array}$ & $\begin{array}{l}3.77 \\
(0.73)\end{array}$ & $4.26(0.68)$ & $\begin{array}{l}3.77 \\
(0.65)\end{array}$ & $2.85(0.83)$ & $1.75(0.87)$ & $\begin{array}{l}< \\
0.001\end{array}$ & $\begin{array}{l}3.75 \\
(0.84)\end{array}$ \\
\hline \multicolumn{9}{|l|}{$\begin{array}{l}\text { Outcome } \\
\text { Measure }\end{array}$} \\
\hline Readiness & $\begin{array}{l}4.25 \\
(0.39)\end{array}$ & $\begin{array}{l}3.90 \\
(0.49)\end{array}$ & $3.56(0.71)$ & $\begin{array}{l}3.46 \\
(0.54)\end{array}$ & $3.12(0.64)$ & $2.86(0.45)$ & $\begin{array}{l}< \\
0.001\end{array}$ & $\begin{array}{l}3.57 \\
(0.62)\end{array}$ \\
\hline \multicolumn{9}{|l|}{$\begin{array}{l}\text { Participant } \\
\text { Characteristics }\end{array}$} \\
\hline Age & $\begin{array}{l}41.71 \\
(13.13)\end{array}$ & $\begin{array}{l}46.69 \\
(11.09)\end{array}$ & $47.06(13.27)$ & $\begin{array}{l}44.96 \\
(10.54)\end{array}$ & $48.85(9.43)$ & $\begin{array}{l}50.53 \\
(12.84)\end{array}$ & 0.12 & $\begin{array}{l}45.94 \\
(11.22)\end{array}$ \\
\hline $\begin{array}{l}\text { Role = } \\
\text { Administrator }\end{array}$ & $\begin{array}{l}2 \\
(11.76)\end{array}$ & $7(6.67)$ & $10(18.87)$ & $\begin{array}{l}38 \\
(18.91)\end{array}$ & $4(15.38)$ & $2(16.67)$ & 0.12 & $\begin{array}{l}63 \\
(15.22)\end{array}$ \\
\hline Years in Role & $\begin{array}{l}6.02 \\
(6.17)\end{array}$ & $\begin{array}{l}8.45 \\
(7.51)\end{array}$ & $9.71(7.52)$ & $\begin{array}{l}8.18 \\
(8.26)\end{array}$ & $10.16(7.65)$ & $\begin{array}{l}12.00 \\
(8.22)\end{array}$ & 0.24 & $\begin{array}{l}8.58 \\
(7.89)\end{array}$ \\
\hline $\begin{array}{l}\text { Ability to } \\
\text { Prescribe }\end{array}$ & $\begin{array}{l}6 \\
(35.29)\end{array}$ & $\begin{array}{l}52 \\
(49.52)\end{array}$ & $33(62.26)$ & $\begin{array}{l}51 \\
(25.37)\end{array}$ & $14(53.85)$ & $10(83.33)$ & $<.001$ & $\begin{array}{l}166 \\
(40.10)\end{array}$ \\
\hline Race $=$ White & $\begin{array}{l}6 \\
(35.29)\end{array}$ & $\begin{array}{l}79 \\
(75.24)\end{array}$ & $41(77.36)$ & $\begin{array}{l}153 \\
(76.12)\end{array}$ & $21(80.77)$ & $11(91.67)$ & 0.005 & $\begin{array}{l}311 \\
(75.12)\end{array}$ \\
\hline $\begin{array}{l}\text { Ethnicity = } \\
\text { Latinx }\end{array}$ & $0(0.0)$ & $4(3.81)$ & $4(7.55)$ & $5(2.49)$ & 2 (7.69) & $0(0.0)$ & 0.37 & $\begin{array}{l}15 \\
(3.62)\end{array}$ \\
\hline $\begin{array}{l}\text { Clinic } \\
\text { Characteristics }\end{array}$ & & & & & & & & \\
\hline
\end{tabular}




\begin{tabular}{|c|c|c|c|c|c|c|c|c|}
\hline \multirow[b]{2}{*}{$\begin{array}{l}\text { Pharmacy On- } \\
\text { Site }\end{array}$} & \multicolumn{7}{|c|}{ Mean (SD) or counts (\%) by group } & \multirow{2}{*}{$\begin{array}{l}\text { Full } \\
\text { Sample } \\
208 \\
(50.24)\end{array}$} \\
\hline & $\begin{array}{l}9 \\
(52.94)\end{array}$ & $\begin{array}{l}46 \\
(43.81)\end{array}$ & $31(58.49)$ & $\begin{array}{l}106 \\
(52.74)\end{array}$ & $12(46.15)$ & $4(33.33)$ & 0.38 & \\
\hline $\begin{array}{l}\text { Insurance } \\
\text { Support On- } \\
\text { Site }\end{array}$ & $\begin{array}{l}16 \\
(94.12)\end{array}$ & $\begin{array}{l}87 \\
(82.86)\end{array}$ & $40(75.47)$ & $\begin{array}{l}160 \\
(79.60)\end{array}$ & $19(73.08)$ & $8(66.67)$ & 0.37 & $\begin{array}{l}330 \\
(79.71)\end{array}$ \\
\hline $\begin{array}{l}\text { Primary Care } \\
\text { Provision }\end{array}$ & $\begin{array}{l}3 \\
(17.65)\end{array}$ & $\begin{array}{l}30 \\
(28.57)\end{array}$ & $15(28.30)$ & $\begin{array}{l}81 \\
(40.30)\end{array}$ & $4(15.38)$ & $5(41.67)$ & 0.03 & $\begin{array}{l}138 \\
(33.33)\end{array}$ \\
\hline \multicolumn{9}{|l|}{$\begin{array}{l}\text { County } \\
\text { Characteristics }\end{array}$} \\
\hline Metropolitan & $\begin{array}{l}14 \\
(82.35)\end{array}$ & $\begin{array}{l}77 \\
(73.33)\end{array}$ & $41(77.36)$ & $\begin{array}{l}135 \\
(67.16)\end{array}$ & $17(65.38)$ & $9(75.0)$ & 0.51 & $\begin{array}{l}293 \\
(70.77)\end{array}$ \\
\hline $\begin{array}{l}\text { HIV } \\
\text { Prevalence }\end{array}$ & $\begin{array}{l}900.88 \\
(889.05)\end{array}$ & $\begin{array}{l}644.49 \\
(625.34)\end{array}$ & $\begin{array}{l}446.87 \\
(464.22)\end{array}$ & $\begin{array}{l}324.41 \\
(386.33)\end{array}$ & $\begin{array}{l}305.46 \\
(156.34)\end{array}$ & $\begin{array}{l}567.33 \\
(462.73)\end{array}$ & $\begin{array}{l}<.001 \\
0.001\end{array}$ & $\begin{array}{l}450.79 \\
(512.89)\end{array}$ \\
\hline $\begin{array}{l}\text { Percent } \\
\text { Poverty }\end{array}$ & $\begin{array}{l}20.43 \\
(4.95)\end{array}$ & $\begin{array}{l}18.45 \\
(5.56)\end{array}$ & $18.07(4.81)$ & $\begin{array}{l}18.57 \\
(5.16)\end{array}$ & $18.51(4.68)$ & $\begin{array}{l}18.17 \\
(6.98)\end{array}$ & 0.74 & $\begin{array}{l}18.53 \\
(5.23)\end{array}$ \\
\hline $\begin{array}{l}\text { Percent } \\
\text { Uninsured }\end{array}$ & $\begin{array}{l}11.48 \\
(3.44)\end{array}$ & $\begin{array}{l}12.25 \\
(3.22)\end{array}$ & $13.17(4.25)$ & $\begin{array}{l}13.22 \\
(3.77)\end{array}$ & $13.24(3.74)$ & $\begin{array}{l}12.39 \\
(3.40)\end{array}$ & 0.15 & $\begin{array}{l}12.87 \\
(3.69)\end{array}$ \\
\hline $\begin{array}{l}\text { Percent } \\
\text { Female (age } \\
\text { 15-44) }\end{array}$ & $\begin{array}{l}21.67 \\
(2.91)\end{array}$ & $\begin{array}{l}21.12 \\
(3.61)\end{array}$ & $20.66(3.19)$ & $\begin{array}{l}19.43 \\
(2.48)\end{array}$ & $20.07(2.67)$ & $\begin{array}{l}19.93 \\
(2.72)\end{array}$ & $\begin{array}{l}<.001 \\
0 .\end{array}$ & $\begin{array}{l}20.17 \\
(3.02)\end{array}$ \\
\hline Percent White & $\begin{array}{l}57.07 \\
(23.10)\end{array}$ & $\begin{array}{l}62.12 \\
(21.89)\end{array}$ & $67.69(16.53)$ & $\begin{array}{l}71.94 \\
(17.39)\end{array}$ & $\begin{array}{l}70.15 \\
(13.66)\end{array}$ & $\begin{array}{l}68.10 \\
(22.07)\end{array}$ & $\begin{array}{l}<.001 \\
0.00\end{array}$ & $\begin{array}{l}68.07 \\
(19.19)\end{array}$ \\
\hline $\begin{array}{l}\text { Percent } \\
\text { Hispanic }\end{array}$ & $\begin{array}{l}6.98 \\
(3.50)\end{array}$ & $\begin{array}{l}8.03 \\
(9.27)\end{array}$ & $11.46(13.93)$ & $\begin{array}{l}8.15 \\
(11.40)\end{array}$ & $\begin{array}{l}15.35 \\
(22.14)\end{array}$ & $6.59(5.21)$ & 0.03 & $\begin{array}{l}8.90 \\
(12.00)\end{array}$ \\
\hline
\end{tabular}

\section{Measures}

CFIR Constructs. The CFIR (21) provides a menu of constructs that can be used as a practical guide for systematically assessing potential barriers and facilitators in preparation for implementing PrEP. Because it is often not practical or necessary to assess all constructs in a single study, evaluations typically focus on a subset of constructs. Constructs for this analysis were selected based on their likelihood of: 1) being a potential barrier (or facilitator) to PrEP implementation and 2) having sufficient variation across clinics. For this analysis, nine different CFIR constructs were considered, based on a literature review and discussions with experts and providers in the field of HIV prevention and implementation science. The constructs covered four CFIR domains, including (1) intervention characteristics (i.e., complexity, relative advantage, and cost), individual characteristics (i.e., staff's attitudes), inner setting factors (i.e., implementation climate, compatibility, leadership engagement, and available resources), and outer setting factors (i.e., cosmopolitanism). All CFIR-related survey items were evaluated on a 5-point Likert scale $(1$ = strongly disagree to 5 = strongly agree). Composite scores for each construct were calculated by taking the average of the contributing survey items.

Complexity was measured using one item: "providing PrEP at my clinic seems easy to do". This measure was reverse coded, so that higher scores indicate higher complexity. Relative advantage was measured using one item: "PrEP would be more effective than interventions we are currently promoting to prevent HIV among patients at our clinic." Cost was measured using five items such as "PrEP is too expensive" (Cronbach's alpha = 0.62). Attitudes were measured using a composite score of 10 items, such as "I am concerned that PrEP is not effective" (Cronbach's alpha $=0.82$ ), where higher scores indicated more concerned or negative attitudes about PrEP. Implementation climate was measured using a composite score of five items, such as "individuals working at my clinic value new types of HIV prevention practices" (Cronbach's alpha $=0.83$ ). Compatibility was measured using a composite score of three items, such as "PrEP seems suitable for patients at my clinic" (Cronbach's alpha = 0.88). Leadership engagement was measured using a composite score of three items, such as: "senior leadership/clinical 
management in my clinic reward clinical innovation and creativity to improve patient care" (Cronbach's alpha $=0.90)$. Available resources was measured using a composite score of four items, such as "we have the necessary support in terms of staffing" (Cronbach's alpha $=0.83$. Cosmopolitanism was measured using one item: "individuals in my clinic are connected with other community organizations that provide HIV prevention services to patients."

Readiness for Implementation. The primary outcome for this study is readiness for implementation of PrEP, which was measured based on steps of the PrEP delivery cascade (i.e., Step 1: HIV risk assessment, Step 2: PrEP education, Step 3: PrEP eligibility assessment, Step 4: PrEP prescription, and Step 5: PrEP follow-up and monitoring) that the clinic could confidently implement. This measure is derived as a composite score based on the 19 or 23 (provider vs. administrator versions) survey items (Cronbach's alpha = 0.92). Survey items include "others in my clinic can counsel a patient on the potential side effects of PrEP" and "others in my clinic can help patients navigate insurance payments regarding PrEP treatment." Responses to each of the survey items follow a Likert scale ( 1 = strongly disagree to $5=$ strongly agree). Readiness for implementation was defined as the average score from the contributing survey items.

Demographic and Clinic/County Characteristics. Individual and clinic-level characteristics were also assessed in the survey. Individual-level characteristics included self-reported age, race (white or non-white), ethnicity (Latinx or not Latinx), role (administrator or provider), years in role, ability to prescribe medicine (yes or no). Clinic-level characteristics included metropolitan location (yes or no), DHHS region (III, IV, or VI), pharmacy on-site (yes or no), staff to provide insurance support onsite (yes or no), presence of primary care services (yes or no). Clinic urban-rural status was defined using the 2013 NCHS urbanrural classification scheme for counties where Metropolitan (urban) includes large central, fringe metro, medium metro, and small metro; and Nonmetropolitan (rural) includes micropolitan and noncore counties (34). Additionally, clinic county characteristics included: HIV prevalence (per 100,000), percent of population under $200 \%$ of the federal poverty level, percent uninsured, percent White, percent Hispanic, percent of women aged 15 to 44 (childbearing age) based on AIDSVu (HIV prevalence rate only) (35) and U.S. Census data (36).

Missing data. The number of missing observations per variable ranged from 0 to 35 . We used a non-parametric missing value imputation for mixed-type data (i.e. continuous and categorical) to impute missing values for all variables described above (including CFIR constructs, readiness for implementation, and demographics and clinic/county characteristics) (see "missForest" package for R (37)).

\section{Statistical Analyses}

Descriptive statistics were performed on all survey items (means (SD) or counts (\%)). Pearson correlations were performed between all CFIR constructs to test for multicollinearity (see Additional File 2 for correlation matrix). Most CFIR measures were significantly correlated with each other, however, there were no strong correlations (all Pearson correlation coefficients are < $|0.50|)$, so multicollinearity was not a major concern.

Using the nine CFIR constructs (complexity, relative advantage, cost, attitudes, implementation climate, compatibility, leadership engagement, available resources, and cosmopolitanism), LPA was performed in R using the "TidyLPA" package (38), to determine if Title $\mathrm{X}$ clinic providers and administrators coalesced into distinct sub-groups. We investigated solutions with one to ten groups. A one group solution would assume that all providers and administrators had similar perceptions across all CFIR measures, which was unlikely; and we assumed that solutions with more than 10 groups would have produced groups that were too small for generalization. To select the number of groups that fit the data best, we used four statistical metrics as well as interpretability of the groups. We considered solutions with high entropy levels (values $>0.80$ indicate a high level of separation between the groups (39)), significant p-values for the bootstrap likelihood ratio test (BLRT) (which tests if the model performs significantly better than the $\mathrm{K}_{-1}$ group solution), and comparatively low AIC and BIC values. Simulation studies have shown that BIC and BLRT perform most reliably in latent profile analyses (40).

Based on the probabilities of class membership, each participant was assigned a group. To understand the composition of each group, bivariate analyses were performed between group membership and individual/clinic-level characteristics (chi-squared was used for categorical variables and one-way ANVOA for continuous variables). We then conducted a random-intercept,

Page 7/15 
multilevel model to test whether group membership predicted readiness for implementation of PrEP, controlling for individual and clinic-level factors. This analysis modeled the nesting of participants within clinics. We fit the model to our data with SAS PROC GLMMIX using maximum likelihood estimation.

\section{Results}

\section{Latent Group Membership}

Based on entropy, BIC, AIC, BLRT, and interpretability, we selected the six group model (entropy $=0.81, \mathrm{AIC}=7880.3, \mathrm{BIC}=8154.1$, BLRT p-value $=0.009$ ) (see Additional File 3 for fit metrics for 1 to 10 group solutions). The 6 group model had high separation between groups (entropy > 0.80), the lowest BIC value, and significant BLRT p-value, indicating that the model performed significantly better than the 5 group solution. The 7 group solution had a lower AIC value compared to the six group model, however, we believed that the 7 group model was less interpretable and had small within-group sample sizes.

Based on their profiles of CFIR-related barriers and facilitators to PrEP implementation the six groups were named: "High Capacity", "Optimistic", "Advantageous", "Moderate", "Incompatible”, and "Resource Constrained" (see Fig. 1). Compared to all other groups, the High Capacity group $(\mathrm{n}=17)$ had the most favorable scores across many CFIR factors including implementation climate (mean $=4.04, S D=0.56)$, compatibility (mean $=4.59, \mathrm{SD}=0.52$ ), leadership engagement $($ mean $=4.59$, $S D=0.48$ ), available resources (mean $=4.32, S D=0.64)$, and cosmopolitanism (mean $=4.65, S D=0.49$ ). They also perceived PrEP implementation to have the lowest complexity (mean $=1.71, \mathrm{SD}=0.69$ ) compared to other groups. The Optimistic group also $(n=105)$ had a favorable profile. It has the second-highest scores for implementation climate ( $m e a n=3.74, S D=0.56)$, compatibility $(4.20, S D=0.43)$, and available resources $(3.04, S D=0.65)$. This group also has the lowest scores for cost (mean $=$ $2.87, \mathrm{SD}=0.44$ ), suggesting that they do not perceive the cost of PrEP to be a major barrier to implementation.

The Advantageous group $(n=53)$ has the highest scores for perceived relative advantage of PrEP implementation (mean $=3.85$, $S D=0.74)$ and second-highest scores for cosmopolitanism $(4.26, S D=0.68)$. However, they also perceived cost $(m e a n=3.89$, $\mathrm{SD}=0.43$ ) as being a major barrier to implementation, with the most unfavorable cost scores compared to any other group. The Moderate group $(n=201)$ had very average scores across all of the CFIR-related barriers and facilitators to implementation (means ranged from 2.9-3.77).

The Incompatible group $(\mathrm{n}=26)$ had unfavorable scores for many of CFIR factors, including the lowest scores for compatibility ( mean $=2.58, S D=0.63)$ and perceived relative advantage $($ mean $=2.23, S D=0.76)$. They also had the most unfavorable scores for complexity (mean $=4.27, \mathrm{SD}=0.60)$ and concerned attitudes about PrEP (mean = 3.04, SD = 0.42). Lastly, the Resource Constrained group $(n=12)$ had the lowest scores for many organizational factors such as available resources $($ mean $=1.58, S D$ $=0.73$ ), leadership engagement (mean $=1.42, S D=0.59)$, implementation climate ( $m e a n=2.30, S D=0.70)$, and cosmopolitanism (mean $=1.75, \mathrm{SD}=0.87)$. They also perceived PrEP also being highly complex $(\mathrm{mean}=4.08, \mathrm{SD}=0.99)$, similar to the incompatible group. Despite these limitations, this group notably has the least concerned attitudes about PrEP (mean = $1.85, \mathrm{SD}=0.47)$, compared to any other group.

Group membership was associated with provider level characteristics (ability to prescribe medication and racial identity), cliniclevel characteristics (provision of primary care services), and county-level characteristics (racial/ethnic composition, HIV rate, and percentage of women of childbearing age) (Table 1).

\section{Readiness for Implementation and Group Membership}

Next, we investigated the association between group membership and readiness for implementation of PrEP, controlling for variables that were significant in bivariate analyses (i.e., ability to prescribe medication, race, provision of primary care, racial/ethnic composition of county, county HIV prevalence, and percentage of women of childbearing age in the county). Compared to the Moderate group, the High Capacity $(B=0.86, S E=0.13, p<0.0001)$ and Optimistic $(B=0.40, S E=0.07, p<$ 
$0.0001)$ groups had significantly higher levels of implementation readiness; and the Resource Constrained group $(B=-0.61, S E=$ $0.17, p=0.0003$ ) had significantly lower levels of implementation readiness (see Fig. 2).

\section{Discussion}

LPA is a useful method for capturing the variation in implementation context and barriers to adoption across sites. In this study, we identified six different sub-groups of family planning providers and administrators that have unique profiles of barriers and facilitators to PrEP implementation. Two groups ("High Capacity" and "Optimistic") showed significantly increased levels of readiness for implementation while one group ("Resource Constrained") showed significantly reduced levels of readiness for implementation of PrEP. To enhance the likelihood of PrEP implementation success in each of these groups, we can employ tailored implementation strategies for overcoming identified weaknesses and leveraging strengths (41-43).

Both the "High Capacity" and "Optimistic" groups (encompassing about $30 \%$ of the sample $(\mathrm{n}=122)$ ) have favorable scores across all of the CFIR factors. These may be ideal clinics to begin the roll-out of PrEP services, since their context is likely able to support PrEP implementation. However, we suggest that all clinics, prior to PrEP implementation, receive a training on the process for conducting the PrEP cascade (i.e. HIV risk assessment, PrEP patient education, assessing patient eligibility for PrEP, PrEP prescription, and PrEP follow-up care) to ensure that clinic staff, providers, and administrators are informed of necessary requirements. We have previously shown that a 1-hour training is able to significantly increase providers' PrEP knowledge, attitudes, and skills (44).

However, the remainder of the groups may need additional implementation strategies beyond training. For instance, the "Advantageous group" ( $n=53,12.8 \%)$, although they believe PrEP offers advantages over their current HIV prevention services, perceive the cost of PrEP to be a major obstacle to implementation. This is understandable as the South has a high proportion of uninsured patients and many states have not expanded Medicaid (45), which can hinder the affordability of PrEP for lowincome and vulnerable patients. To overcome cost hurdles, there are some services in place, such as HHS's "Ready, Set, PrEP" Program and Gilead's Advancing Access Program, which cover the cost of PrEP prescriptions for uninsured patients. Gilead also has a co-pay program to help insured patients cover the cost of co-pays and deductibles for PrEP services. Many of the "Advantageous group" clinics already have staff on site that assist patients with insurance enrollment (75\%), and these insurance navigators should receive education on procedures for enrolling patients in these PrEP payment assistance programs. Additionally, clinics that are concerned about the cost of PrEP and have limited financial resources can also consider pursuing grant funding for PrEP services, as this has been a facilitator for implementation in other family planning clinics (16).

Furthermore, for successful PrEP implementation to occur in the "Incompatible" and "Resource Constrained" groups, which represent about $9 \%$ of the sample $(n=38)$, significant amounts of system strengthening as well as building a "business case" for PrEP delivery are likely needed. Specifically, the "Incompatible group" had the most negative attitudes about PrEP and perceived that PrEP was not compatible with services currently offered in their setting. These negative attitudes about PrEP are concerning, given that the southern US is the current epicenter of the HIV epidemic (2). Providers and staff in this group may require additional education on the prevalence and impacts of HIV to overcome knowledge/attitude barriers. In addition, the "Incompatible" group believed that PrEP implementation was too complex. Although there is limited guidance on strategies to combat issues related to complexity, expert recommendations suggest that "promoting adaptability" may work for these settings (41). Promoting adaptability requires tailoring the intervention (i.e. PrEP) to the site's needs (23). For instance, our research in family planning clinics has shown that some clinics have decided to provide the initial steps of the PrEP cascade (HIV risk assessment and PrEP patient education) and then refer patients to external providers for PrEP prescriptions and continued care (16). Clinics in the "Incompatible" group may consider this referral adaption, so that women who could benefit from PrEP are at a minimum educated and made aware of the availability of PrEP services in their community. Universal education pertaining to PrEP is especially important given consistently low knowledge and awareness about PrEP reported among women (5). Other potential adaptations to PrEP, that could help overcome barriers, include pharmacy-based PrEP services (which could be useful for clinics that have a pharmacy on-site) (46), telemedicine (47), and at-home PrEP services (48). 
However, in the "Resource Constrained group" it may be unlikely that any PrEP services could be offered without significant additional internal and external systems changes. This group has clinic characteristics (low implementation climate, available resources, leadership engagement) that are very unfavorable for successful implementation. They also have very low cosmopolitanism scores, suggesting that even the adaptation strategy recommended for the "Incompatible" group would be ineffective, since they do not have relationships with external HIV organizations where they could refer patients. Not only would these clinics need to build partnerships with external HIV organizations and PrEP providers, they would also need to identify strong champions to lead the adoption of PrEP services in their clinic (to overcome climate and leadership weaknesses) and pursue grant funding (to overcome cost and resource barriers) (41).

Future research should focus on the provision of these tailored implementation plans to each sub-group of clinics. Evaluations would yield important data on the success of these implementation strategies to promote PrEP adoption and sustained delivery in each clinic sub-group. Limitations of this study include the use of a non-probability sampling method and self-reported data (i.e. not based on observations of clinical context). Additionally, some of the groups had small within-group sample sizes, so these groups may not generalize to the larger population of Title $\mathrm{X}$ clinics. Furthermore, we were unable to examine all CFIR constructs. CFIR is comprised of 39 different constructs and although our survey captured the majority of these, we were unable to utilize all constructs in the LPA. If too many constructs are included in this analysis, it can become difficult to interpret; therefore, we selected nine CFIR constructs that we hypothesized to have the greatest impact on PrEP implementation as well as

the greatest variability across clinical settings. These decisions were made based on discussions with experts in implementation science and HIV prevention as well as clinical providers. Despite limitations, the LPA approach may be especially helpful for large public health systems, like the Title X Family Planning Program, which provides funding for the provision of family planning and other preventative health services for un- and under-insured individuals through a network of approximately 4000 clinical sites across the U.S. Learning if there are systematic differences within the network that could support more tailored implementation planning might allow for these networks to more easily scale interventions across sites, especially when interventions may be required at the Title $\mathrm{X}$ level.

\section{Conclusion}

In conclusion, we identified six different groups of Title X family planning clinics, based on their profiles of CFIR-related determinants of PrEP implementation. Some groups had very favorable scores across the CFIR factors as well as high readiness for implementation, suggesting an ideal environment for roll-out of PrEP services. Other groups, with identified CFIR-associated weaknesses, would likely need system strengthening prior to PrEP implementation along with tailored implementation strategies to overcome barriers to successful PrEP implementation. LPA has important implications for engaging with complexity in implementation research and understanding the contextual variation across sites. This method also promotes identification of subgroups, allowing implementation planning to be tailored to the specific needs of unique segments of this diverse network of clinical sites comprising the Title $\mathrm{X}$ family planning safety net system.

\section{List Of Abbreviations}

Akaike information criterion (AIC)

Bayesian information criterion (BIC)

Bootstrap likelihood ratio test (BLRT)

Consolidated Framework for Implementation Research (CFIR)

Evidence-based interventions (EBIs)

Human immunodeficiency virus (HIV)

Latent Profile Analysis (LPA)

Page 10/15 
National Clinical Training Center for Family Planning (NCTCFP)

Pre-exposure prophylaxis (PrEP)

United States (U.S)

United States Department of Health and Human Services (USDHHS)

\section{Declarations}

\section{Ethics approval and consent to participate}

Approval to conduct the study was gained from Emory University and University of North Carolina Institutional Review Boards.

\section{Consent for publication}

All participants provided consent before participating in the survey.

\section{Availability of data and materials}

The datasets analyzed during the current study are available from the corresponding author on reasonable request.

\section{Competing interests}

JS and AS received grant funding from Gilead Sciences, Inc, to Emory University for unrelated work.

\section{Funding}

This research was supported by the $\mathrm{NIH}$-funded Adolescent Medicine Trials Network for HIV/AIDS Interventions (ATN) grant U24HD089880. The content is solely the responsibility of the authors and does not necessarily represent the official views of the National Institutes of Health.

\section{Authors' contributions}

$\mathrm{KP}$ analyzed the data, interpreted the findings, and wrote the manuscript. RH contributed to data analysis and interpretation. $\mathrm{CE}$, AS and JS conceptualized and designed the study. All authors approved the final manuscript.

\section{Acknowledgements}

Not Applicable

\section{References}

1. Centers for Disease. Control and Prevention. HIV surveillance report. 2017.

2. Centers for Disease Control Prevention. CDC issue brief: HIV in the Southern United States. 2016.

3. Fonner VA, Dalglish SL, Kennedy CE, Baggaley R, O'reilly KR, Koechlin FM, et al. Effectiveness and safety of oral HIV preexposure prophylaxis for all populations. AIDS. 2016;30(12):1973.

4. US Food Drug Administration. FDA approves first drug for reducing the risk of sexually acquired HIV infection. 2012. 
5. Patel AS, Goparaju L, Sales JM, Mehta CC, Blackstock OJ, Seidman D, et al PrEP Eligibility Among At-Risk Women in the Southern United States: Associated Factors, Awareness, and Acceptability. Journal of acquired immune deficiency syndromes (1999). 2019;80(5):527.

6. Seidman D, Carlson K, Weber S, Witt J, Kelly PJ. United States family planning providers' knowledge of and attitudes towards preexposure prophylaxis for HIV prevention: a national survey. Contraception. 2016;93(5):463-9.

7. Sales JM, Phillips AL, Tamler I, Munoz T, Cwiak C, Sheth AN. Patient recommendations for PrEP information dissemination at family planning clinics in Atlanta, Georgia. Contraception. 2019;99(4):233-8.

8. Calabrese SK, Dovidio JF, Tekeste M, Taggart T, Galvao RW, Safon CB, et al HIV pre-exposure prophylaxis stigma as a multidimensional barrier to uptake among women who attend planned parenthood. Journal of acquired immune deficiency syndromes (1999). 2018;79(1):46.

9. Sullivan PS, Mouhanna F, Mera R, Pembleton E, Castel AD, Jaggi C, et al. Methods for county-level estimation of preexposure prophylaxis coverage and application to the US Ending the HIV Epidemic jurisdictions. Annals of epidemiology. 2020.

10. Sullivan PS, Giler RM, Mouhanna F, Pembleton ES, Guest JL, Jones J, et al. Trends in the use of oral emtricitabine/tenofovir disoproxil fumarate for pre-exposure prophylaxis against HIV infection, United States, 2012-2017. Ann Epidemiol. 2018;28(12):833-40.

11. Smith DK, Van Handel M, Grey J. Estimates of adults with indications for HIV pre-exposure prophylaxis by jurisdiction, transmission risk group, and race/ethnicity, United States, 2015. Ann Epidemiol. 2018;28(12):850-7. e9.

12. Ya-lin AH, Zhu W, Smith DK, Harris N, Hoover KW. HIV preexposure prophylaxis, by race and ethnicity-United States, 20142016. Morb Mortal Wkly Rep. 2018;67(41):1147.

13. Siegler AJ, Mouhanna F, Giler RM, Weiss K, Pembleton E, Guest J, et al. The prevalence of pre-exposure prophylaxis use and the pre-exposure prophylaxis-to-need ratio in the fourth quarter of 2017, United States. Ann Epidemiol. 2018;28(12):841-9.

14. Siegler AJ, Bratcher A, Weiss KM. Geographic Access to Preexposure Prophylaxis Clinics Among Men Who Have Sex With Men in the United States. American journal of public health. 2019;109(9):1216-23.

15. Siegler AJ, Bratcher A, Weiss KM, Mouhanna F, Ahlschlager L, Sullivan PS. Location location location: an exploration of disparities in access to publicly listed pre-exposure prophylaxis clinics in the United States. Ann Epidemiol. 2018;28(12):858-64.

16. Sales J, Piper K, Escoffery C, Sheth A. 3. Where Can Southern Girls go for Prep? Examining the Prep-Providing Practices of Title-X Funded Family Planning Clinics Across the Southern US. J Adolesc Health. 2020;66(2):2.

17. Auerbach JD, Kinsky S, Brown G. Charles V. Knowledge, attitudes, and likelihood of pre-exposure prophylaxis (PrEP) use among US women at risk of acquiring HIV. AIDS Patient Care STDs. 2015;29(2):102-10.

18. Stormo AR, Saraiya M, Hing E, Henderson JT, Sawaya GF. Women's clinical preventive services in the United States: who is doing what? JAMA internal medicine. 2014;174(9):1512-4.

19. Fauci AS, Redfield RR, Sigounas G, Weahkee MD, Giroir BP. Ending the HIV epidemic: a plan for the United States. Jama. 2019;321(9):844-5.

20. Flottorp SA, Oxman AD, Krause J, Musila NR, Wensing M, Godycki-Cwirko M, et al. A checklist for identifying determinants of practice: a systematic review and synthesis of frameworks and taxonomies of factors that prevent or enable improvements in healthcare professional practice. Implementation Science. 2013;8(1):35.

21. Damschroder LJ, Aron DC, Keith RE, Kirsh SR, Alexander JA, Lowery JC. Fostering implementation of health services research findings into practice: a consolidated framework for advancing implementation science. Implementation science. 2009;4(1):50.

22. Sales J. Pre-Exposure Prophylaxis Implementation in Family Planning Services across the Southern United States: Findings from a survey among staff, providers and administers working in Title X-funded Clinics (under review). AIDS \& Behavior. 2020.

23. Waltz TJ, Powell BJ, Chinman MJ, Smith JL, Matthieu MM, Proctor EK, et al. Expert recommendations for implementing change (ERIC): protocol for a mixed methods study. Implementation Science. 2014;9(1):39. 
24. Powell BJ, Beidas RS, Lewis CC, Aarons GA, McMillen JC, Proctor EK, et al. Methods to improve the selection and tailoring of implementation strategies. J Behav Health Serv Res. 2017;44(2):177-94.

25. Powell BJ, Fernandez ME, Williams NJ, Aarons GA, Beidas RS, Lewis CC, et al. Enhancing the impact of implementation strategies in healthcare: a research agenda. Frontiers in public health. 2019;7:3.

26. Wensing M, Bosch M, Grol R. Selecting, tailoring, and implementing knowledge translation interventions. Knowledge Translation in health care: Moving from evidence to practice. 2009;94:113.

27. Aarons GA, Cafri G, Lugo L, Sawitzky A. Expanding the domains of attitudes towards evidence-based practice: the evidence based practice attitude scale-50. Administration policy in mental health mental health services research. 2012;39(5):33140.

28. Jacobs SR, Weiner BJ, Bunger AC. Context matters: measuring implementation climate among individuals and groups. Implementation Science. 2014;9(1):46.

29. Ganju V. Implementation of evidence-based practices in state mental health systems: Implications for research and effectiveness studies. Schizophr Bull. 2003;29(1):125-31.

30. Raghavan R, Bright CL, Shadoin AL. Toward a policy ecology of implementation of evidence-based practices in public mental health settings. Implementation Science. 2008;3(1):26.

31. Jason L, Glenwick D. Handbook of methodological approaches to community-based research: Qualitative, quantitative, and mixed methods: Oxford university press; 2016.

32. Oberski D. Mixture models: Latent profile and latent class analysis. Modern statistical methods for: Springer; 2016. pp. 27587.

33. Sales JM, Escoffery C, Hussen SA, Haddad LB, Phillips A, Filipowicz T, et al. Pre-Exposure Prophylaxis Integration into Family Planning Services at Title X Clinics in the Southeastern United States: A Geographically-Targeted Mixed Methods Study (Phase 1 ATN 155). JMIR research protocols. 2019;8(6):e12774.

34. 34 .

35. 2015 HIV Prevalence Data Emory University. Rollins School of Public Health. Atlanta, GA: AIDSVu; [Available from: www.aidsvu.org.

36. US Census Bureau. Profile of general population and housing characteristics: 2010. 2010.

37. Stekhoven DJ, Bühlmann P. MissForest-non-parametric missing value imputation for mixed-type data. Bioinformatics. 2012;28(1):112-8.

38. Rosenberg J, van Lissa C, Beymer P, Anderson D, Schell M, Schmidt J. tidyLPA. Easily carry out Latent Profile Analysis (LPA) using open-source or commercial software [R package]. 2019.

39. Celeux G, Soromenho G. An entropy criterion for assessing the number of clusters in a mixture model. Journal of classification. 1996;13(2):195-212.

40. Nylund KL, Asparouhov T, Muthén BO. Deciding on the number of classes in latent class analysis and growth mixture modeling: A Monte Carlo simulation study. Structural equation modeling: A multidisciplinary Journal. 2007;14(4):535-69.

41. Waltz TJ, Powell BJ, Fernández ME, Abadie B, Damschroder LJ. Choosing implementation strategies to address contextual barriers: diversity in recommendations and future directions. Implementation Science. 2019;14(1):42.

42. Powell BJ, Beidas RS, Lewis CC, Aarons GA, McMillen JC, Proctor EK, et al. Methods to Improve the Selection and Tailoring of Implementation Strategies. J Behav Health Serv Res. 2017;44(2):177-94.

43. Proctor EK, Powell BJ, McMillen JC. Implementation strategies: recommendations for specifying and reporting. Implementation Science. 2013;8(1):139.

44. Sales JM, Cwiak C, Haddad LB, Phillips A, Powell L, Tamler I, et al. Brief Report: Impact of PrEP Training for Family Planning Providers on HIV Prevention Counseling and Patient Interest in PrEP in Atlanta, Georgia. J Acquir Immune Defic Syndr. 2019;81(4):414-8.

45. Berchick ER, Hood E, Barnett JC. Health insurance coverage in the United States: 2017. Current population reports Washington: US Government Printing Office; 2018. 
46. Tung EL, Thomas A, Eichner A, Shalit P. Implementation of a community pharmacy-based pre-exposure prophylaxis service: a novel model for pre-exposure prophylaxis care. Sex Health. 2018;15(6):556-61.

47. Hoth AB, Shafer C, Dillon DB, Mayer R, Walton G, Ohl ME. lowa TelePrEP: a public-health-partnered telehealth model for human immunodeficiency virus preexposure prophylaxis delivery in a rural state. Sexually transmitted diseases.

2019;46(8):507-12.

48. Siegler AJ, Mayer KH, Liu AY, Patel RR, Ahlschlager LM, Kraft CS, et al. Developing and assessing the feasibility of a homebased preexposure prophylaxis monitoring and support program. Clin Infect Dis. 2019;68(3):501-4.

\section{Figures}

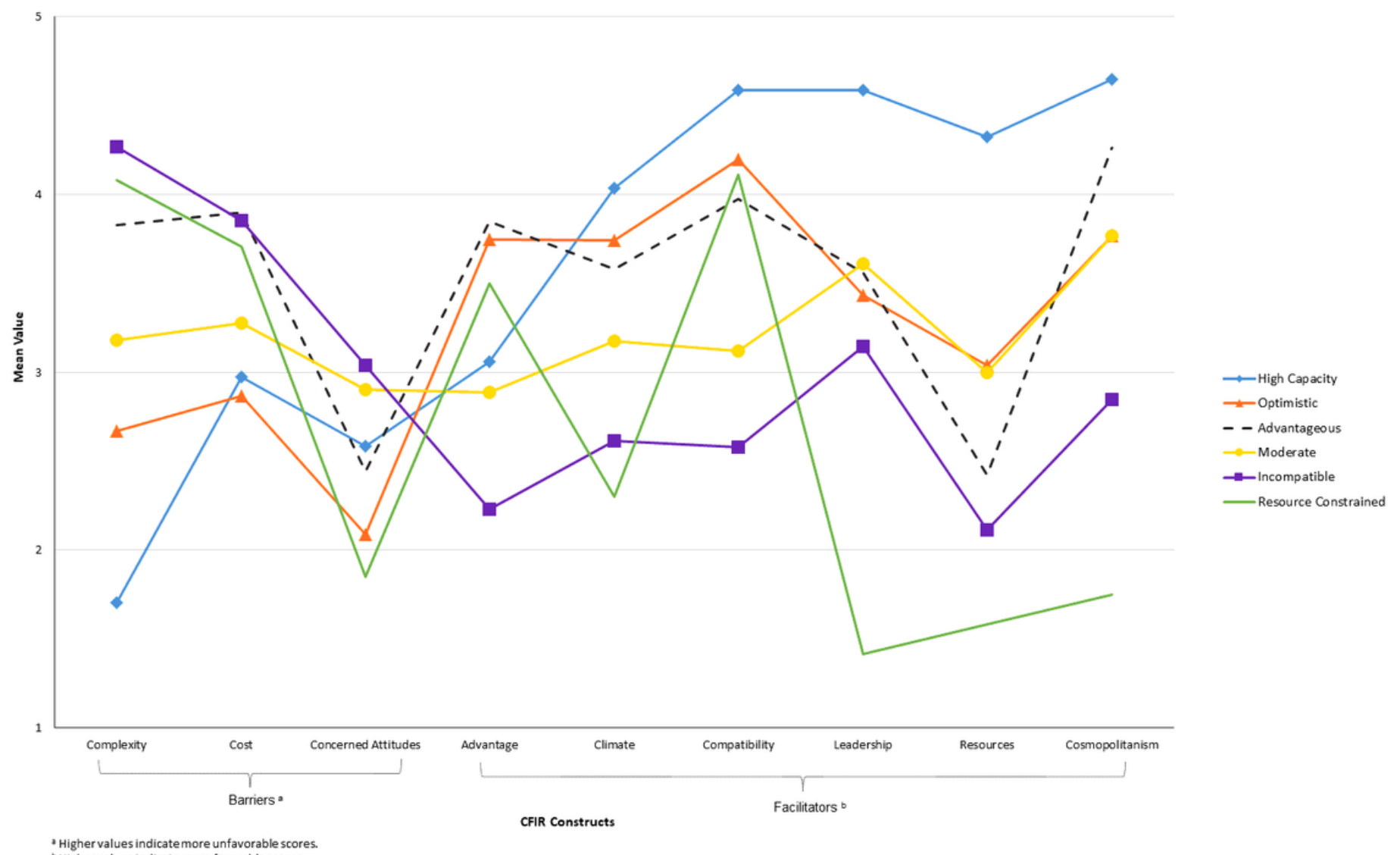

Figure 1

Profile plot: Mean scores across CFIR measures, by group 


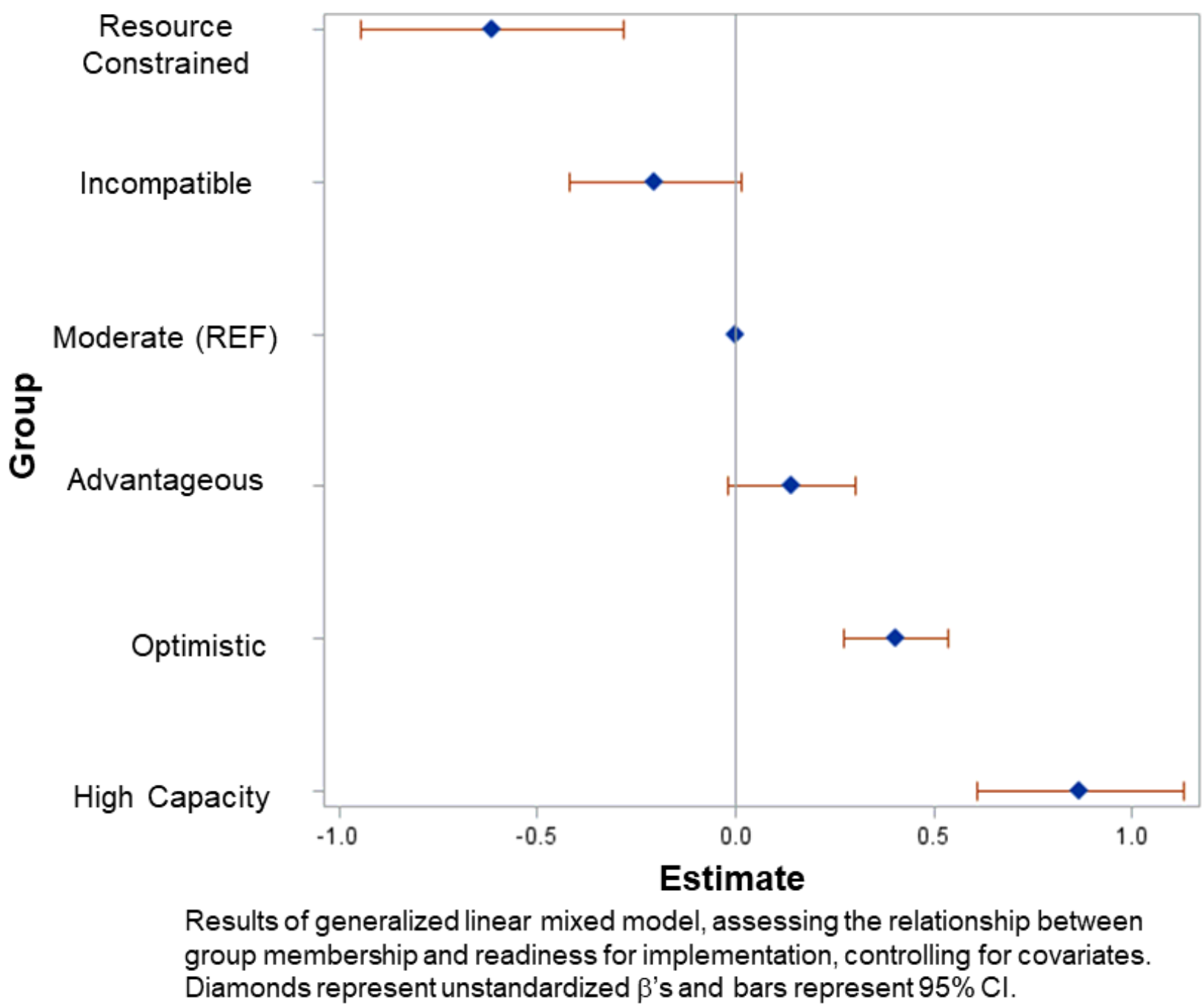

Figure 2

Relationship between group membership and readiness for implementation of PrEP.

\section{Supplementary Files}

This is a list of supplementary files associated with this preprint. Click to download.

- AdditionalFile3.docx

- AdditionalFile2.docx

- AdditionalFile1.docx 